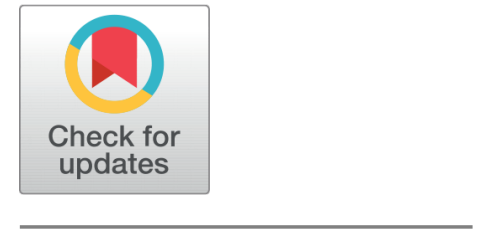

OPEN ACCESS

Received: 14-06-2020

Accepted: 28-07-2020

Published: 11.09 .2020

Editor: Dr. Natarajan Gajendran

Citation: Prabhakar B, Wani TA (2020) First principle energy calculation of YBCO superconductor. Indian Journal of Science and Technology 13(33): 3425-3429. https ://doi.org/10.17485/IJST/v13i33.926

*Corresponding author.

budigiprabhakar@gmail.com

Funding: None

Competing Interests: None

Copyright: @ 2020 Prabhakar \& Wani. This is an open access article distributed under the terms of the Creative Commons Attribution License, which permits unrestricted use, distribution, and reproduction in any medium, provided the original author and source are credited.

Published By Indian Society for Education and Environment (iSee)

ISSN

Print: 0974-6846

Electronic: 0974-5645

\section{First principle energy calculation of YBCO superconductor}

\author{
Budigi Prabhakar ${ }^{1 *}$, Tanveer Ahmad Wani ${ }^{1}$ \\ 1 Department of Physics, Noida International University, Greater Noida, 201310, Uttar \\ Pradesh, India
}

\section{Abstract}

Background/Objectives: The crystal structure of YBCO Superconductor has fascinated the material science research group. The calculation of elastic constants, enthalpy and final energy of YBCO superconductor under pressure up to $30 \mathrm{GPa}$ are further investigated in this research study. Methods: The pressure dependence of the elastic constants of the $\mathrm{YBa}_{2} \mathrm{Cu}_{3} \mathrm{O}_{7}(\mathrm{YBCO})$ is investigated using the first principle calculations based on the density functional theory (DFT). The only input required is the lattice parameters at corresponding pressure of materials which are predicted using first principle computational methods at desired high-pressure state. Findings: The elastic constants, enthalpy and final energy of the YBCO Superconductor has been calculated by using ab- initio calculations. The enthalpy formation is the first value considered from the Density Functional Theory (DFT). Applications: This will explain elastic constants accurately as a function of composition. This enables the use of material optimization techniques to develop new materials that are systematically adapted to specific components.

Keywords: YBCO superconductor; density functional theory (DFT); elastic constants; pressure; enthalpy

\section{Introduction}

The discovery of the Ba-La-Cu-O system by Muller and Bednortz ${ }^{(1)}$ with a $\mathrm{T}_{s c}$ of $30 \mathrm{~K}$ has generated and further research has led Wu et al to the discovery of $\mathrm{T}_{s c}$ of $90 \mathrm{~K}$. In 1964, Schooley and coworkers first reported superconductivity in $\mathrm{SrTiO}_{3}$, an oxide with parvoskite crystal structure, with a quite low transition temperature, $\mathrm{T}_{c}=0.3 \mathrm{~K}$. In 1975, Coworkers and Sleight found high transition temperature at $13 \mathrm{~K}$ in $\mathrm{BaPb}_{1-x} \mathrm{Bi}_{x} \mathrm{O}_{3}$. In 1986, Bednortz and Muller reported a remarkable superconducting transition at $30 \mathrm{~K}$ in $\mathrm{LaBaCuO}_{3}$ (LBCO). Almost one year later, $\mathrm{Wu}$ and colleagues reported superconductivity in $\mathrm{YBa}_{2} \mathrm{Cu}_{3} \mathrm{O}_{7}(\mathrm{YBCO})$, with $\mathrm{Tc}=90 \mathrm{~K}$. The discovery of the Ba-La$\mathrm{Cu}-\mathrm{O}$ system by Bednortz and Muller with a superconducting transition temperature of $30 \mathrm{~K}$ has generated a great deal of tremendous interest among physicists ${ }^{(2)}$. In 1964, Schooley and coworkers first reported superconductivity in $\mathrm{SrTiO}_{3}$, an oxide with parvoskite crystal structure, with a quite low transition temperature, $\mathrm{T}_{c}=0.3 \mathrm{~K}$. In 1975, Coworkers and Sleight found high transition temperature at $13 \mathrm{~K}$ in $\mathrm{BaPb}_{1-x} \mathrm{Bi}_{x} \mathrm{O}_{3}$. In 1986, Bednortz and Muller reported a remarkable superconducting transition at 
$30 \mathrm{~K}$ in $\mathrm{LaBaCuO}_{3}$ (LBCO). Almost one year later, Wu and colleagues reported superconductivity in $\mathrm{YBa}_{2} \mathrm{Cu}_{3} \mathrm{O}_{7}$, with $\mathrm{Tc}=$ $90 \mathrm{~K}^{(3)}$. The pressure dependence on sound velocities and elastic modulii ${ }^{(4)}$, pressure dependence of specific heat and Debye temperature of internal friction and linear thermal expansivity. The anomalous stiffing below critical temperature observed in poly crystals was also reported in single crystals. As for the mono crystalline elastic constants, only one set of complete Cij derived from the phonon frequencies of an elastic scattering for a tetragonal structure was reported ${ }^{(5)}$. Using sound velocity measurements, Saint Paul and coworkers ${ }^{(6)}$ estimated $\mathrm{C}_{33}$ and $\mathrm{C}_{44}$. Also, from sound velocities, Golding and coworkers calculated the pseudo tetragonal elastic constants $\mathrm{C}_{11}$ and $\mathrm{C}_{33}$. Baumgart and coworkers ${ }^{(7)}$ determined $\mathrm{C}_{11}$, C33and $\mathrm{C}_{44}$. The elastic properties of YBCO superconductor were studied by Vetebskii and coworkers. Starting from the mean field energy, Millis and Rabe derived expressions for the singularity's behavior of the elastic constants and sound velocities near Tc. Calculation of Elastic constants, enthalpy and final energy values at different pressures for $\mathrm{YBa}_{2} \mathrm{Cu}_{3} \mathrm{O}_{7}$ (YBCO) Superconductor is the main focus in the present study.

\section{Theory and computational details}

Furthermore, one can also directly obtain some useful information on the characteristics of bonding and the structural stability of a crystal. The elastic constants $C_{i j k l}$ with respect to the finite strain variables is defined as ${ }^{(8)}$

$$
C_{i j}=\left(\frac{\partial \sigma_{i j}(X)}{\partial e_{k l}}\right)_{x}
$$

Where $\sigma_{i j}$ and $\mathrm{e}_{k l}$ are the applied stress and Eulerian strain tensors and $\mathrm{X}$ and $\mathrm{x}$ are the coordinates before and after the deformation. For the isotropic stress, we have ${ }^{(9)}$

$$
\begin{gathered}
C_{i j k l}=c_{i j k l}+\frac{P}{2}\left(2 \delta_{i j} \delta_{k l}-\delta_{i l} \delta_{j k}-\delta_{i k} \delta_{j i}\right) \\
C_{i j k l}=\left(\frac{1}{V(X)} \frac{\partial^{2} E(X)}{\delta e_{i j} \delta e_{k l}}\right)_{x}
\end{gathered}
$$

Where $\mathrm{C}_{i j k l}$ denotes the second-order derivatives. The Strain energy - strain curve has been used for calculation of elastic constants purpose. All the elastic constants increase with pressure. For orthorhombic crystal the mechanical stability is represented by the following condition ${ }^{(10)}$.

$$
\begin{gathered}
C_{11}>0, C_{22}>0, C_{33}>0, C_{44}>0, C_{55}>0 \\
C_{66}>0\left[C_{11}+C_{22}+C_{33}+2\left(C_{12}+C_{13}+C_{23}\right)\right]>0 \\
\left(C_{11}+C_{22}-2 C_{12}\right)>0 \\
\left(C_{11}+C_{33}-2 C_{13}\right)>0 \\
\left(C_{22}+C_{33}-2 C_{23}\right)>0
\end{gathered}
$$

The superconductor having tetragonal symmetry considered here comes under the second category and the six nonzero elastic constants for it are $\mathrm{C}_{11}, \mathrm{C}_{33}, \mathrm{C}_{44}, \mathrm{C}_{66}, \mathrm{C}_{12}$ and $\mathrm{C}_{13}$. The equations for the wave propagation in the tetragonal crystal are very easily obtained from the equations for the orthorhombic crystal by making the substitutions $C_{11}=C_{22}, C_{44}=C_{55}$ and $C_{13}=C_{23}$. Enthalpy of formation was assessed from GGA $+\mathrm{U}$ ab- initio Density Functional Theory (DFT) based calculations. The electronic structure and total energies of $\mathrm{YBa}_{2} \mathrm{Cu}_{3} \mathrm{O}_{7}$ and the constituent oxides, $\mathrm{YO}_{5}, \mathrm{Ba}_{2} \mathrm{O}$, and $\mathrm{Cu}_{3} \mathrm{O}$, were calculated by means MedeaVASP $^{(11)}$ program using projector augmented plane waves basis set and generalized gradient approximation (GGA-PBE) ${ }^{(12)}$ to exchange-correlation functional combined with additional local orbital specific coulomb potential $\mathrm{U}=3 \mathrm{eV}$ acting on $\mathrm{Cu}-3 \mathrm{~d}$ states. The first value considered from Density Functional Theory (DFT) is Enthalpy formation. The final energy of the YBCO Superconductor has been calculated by using ab- initio calculations. 


\section{Results and Discussion}

Knowledge of elastic constants are significant for understanding of the structural stability and properties of the crystal. The elastic constants under different pressures obey these stability criteria, implying that the orthorhombic $\mathrm{YBa}_{2} \mathrm{Cu}_{3} \mathrm{O}_{7}$ is mechanically stable. The present results at ground state $\mathrm{C}_{11}=1580 \mathrm{Gpa}, \mathrm{C}_{12}=713 \mathrm{Gpa}, \mathrm{C}_{13}=278 \mathrm{Gpa}, \mathrm{C}_{22}=-385 \mathrm{Gpa}, \mathrm{C}_{23}=-$ $1177 \mathrm{Gpa}, \mathrm{C}_{33}=1355 \mathrm{Gpa}, \mathrm{C}_{44}=449 \mathrm{Gpa}, \mathrm{C} 5=328 \mathrm{Gpa}, \mathrm{C} 66=668 \mathrm{Gpa}$ and at $20 \mathrm{Gpa} \mathrm{C}_{11}=5348, \mathrm{C}_{12}=2409 \mathrm{Gpa}, \mathrm{C}_{13}=1888 \mathrm{Gpa}$, $\mathrm{C}_{22}=5804 \mathrm{Gpa}, \mathrm{C}_{23}=1729 \mathrm{Gpa}, \mathrm{C}_{33}=4813 \mathrm{Gpa}, \mathrm{C}_{44}=1021 \mathrm{Gpa}, \mathrm{C}_{55}=1090 \mathrm{Gpa}, \mathrm{C}_{66}=1331 \mathrm{Gpa} . \mathrm{C}_{11}, \mathrm{C}_{22}$, and $\mathrm{C}_{33}$ represent the resistance to linear compression, and the other elastic constants are mainly associated with the elasticity in shape. In the entire pressure range of our calculations, $\mathrm{C}_{11}=5384 \mathrm{Gpa}, \mathrm{C}_{22}=5804 \mathrm{Gpa}$ and $\mathrm{C}_{33}=4813 \mathrm{Gpa}$, were much larger than those of the other elastic constants. Further, the relationship $c_{22}>c_{11}>c_{33}$ under different pressures implied that the strength of the bonding along the [010] direction was stronger than those along the [001] and [100] directions. The calculated values of Elastic constants at different pressures are given in Table 1 and corresponding values versus pressure for YBCO superconductor is shown in Figure 1.

As can be seen from Table 1, all the elastic constants increase with pressure. The anisotropy factor A was obtained from the relation $\mathrm{A}=2 \mathrm{C}_{44} / \mathrm{C}_{11}-\mathrm{C}_{12}$. The difference between single crystalline elastic constants, $\mathrm{C}_{12}-\mathrm{C}_{44}$ is well-known as the Cauchy pressure. A positive value of $\mathrm{C}_{12}-\mathrm{C}_{44}$ indicates the metallic bonding, whereas negative value significances covalent bonding. The Cauchy pressures positive value always indicates ductile nature, while a negative value corresponds to brittleness. The calculated values of enthalpy and final energy up to $30 \mathrm{GPa}$ are given in Table 2.f The enthalpy and final energy versus pressure for YBCO superconductor is shown in Figure 2. The minimum enthalpy and final energy is $-2086.638 \mathrm{KJ} \mathrm{mol}^{-1}$ and -2086.65 at ground state and $-2084.43 \mathrm{KJ} \mathrm{mol}^{-1}$ and -2086.60 at $30 \mathrm{GPa}$. From these results it is clear that the enthalpy and final energy of YBCO superconductor increases with pressure.

Table 1. Calculated Values of elastic constants $\mathrm{C}_{i j}(\mathrm{GPa})$ of $\mathrm{YBa}_{2} \mathrm{Cu}_{3} \mathrm{O}_{7}$ under pressure

\begin{tabular}{llllllllll}
\hline Pressure & C11 & C12 & C13 & C22 & C23 & C33 & C44 & C55 & C66 \\
\hline 0 & 1,580 & 713 & 278 & -385 & $-1,177$ & 1,355 & 449 & 328 & 668 \\
10 & 4,345 & 1,974 & 1,413 & 4,726 & 1,377 & 3,877 & 889 & 886 & 1,152 \\
20 & 5,348 & 2,409 & 1,888 & 5,804 & 1,729 & 4,813 & 1,021 & 1,090 & 1,331 \\
\hline
\end{tabular}

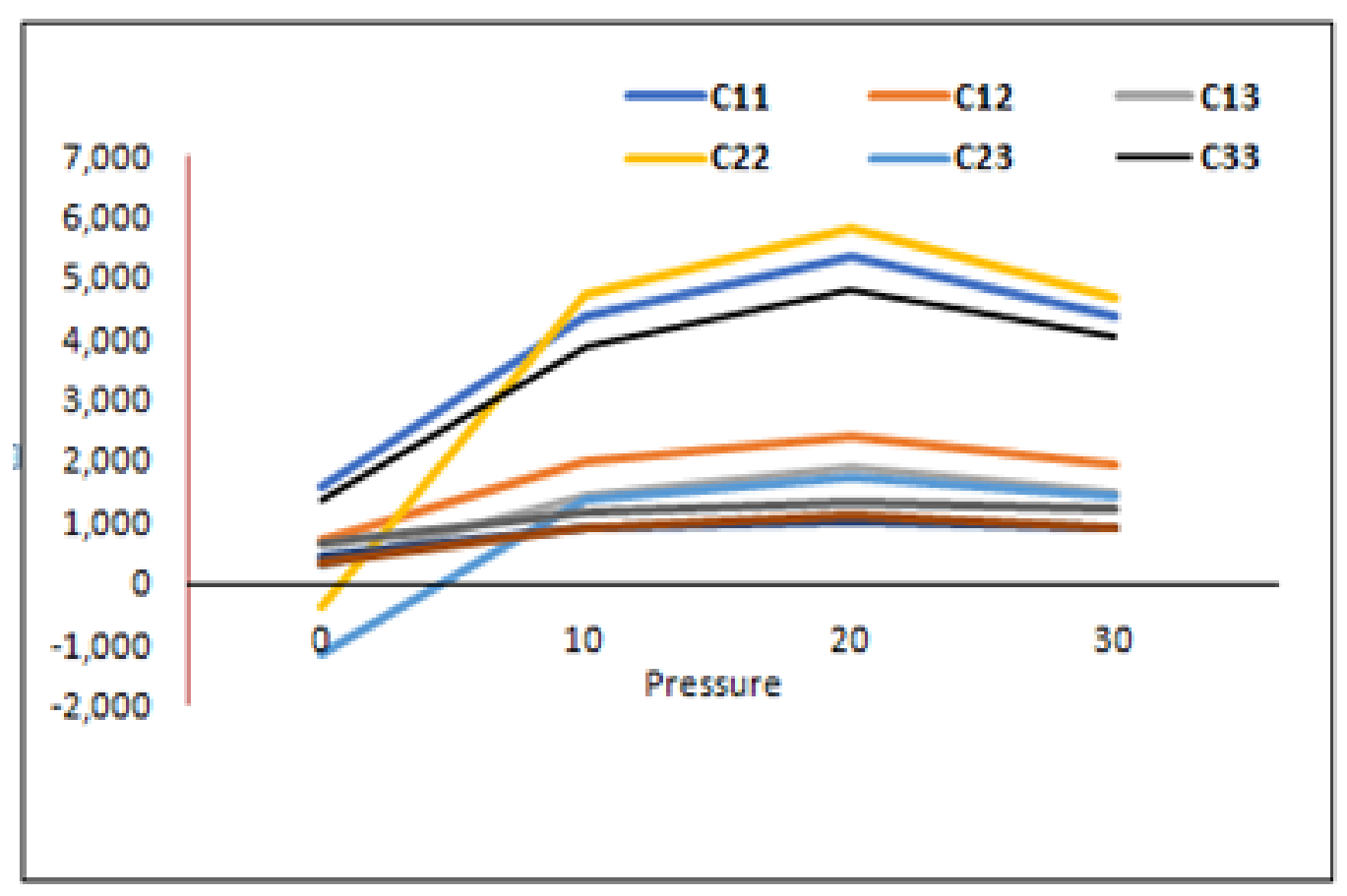

Fig 1. Elastic constants versus pressure for YBCO superconductor 
Table 2. Calculated values of enthalpy and Final energy at different Pressures

\begin{tabular}{lll}
\hline Pressure $(\mathbf{G P a})$ & Minimum enthalpy $\left(\mathrm{KJ} \mathrm{mol}^{\mathbf{- 1}}\right)$ & Final energy of the fully relaxed structure \\
\hline 0 & $-2,086.638$ & $-2,086.65$ \\
10 & $-2,085.81$ & $-2,086.64$ \\
20 & -2085.156659 & -2086.630299 \\
30 & $-2,084.43$ & $-2,086.60$ \\
\hline
\end{tabular}

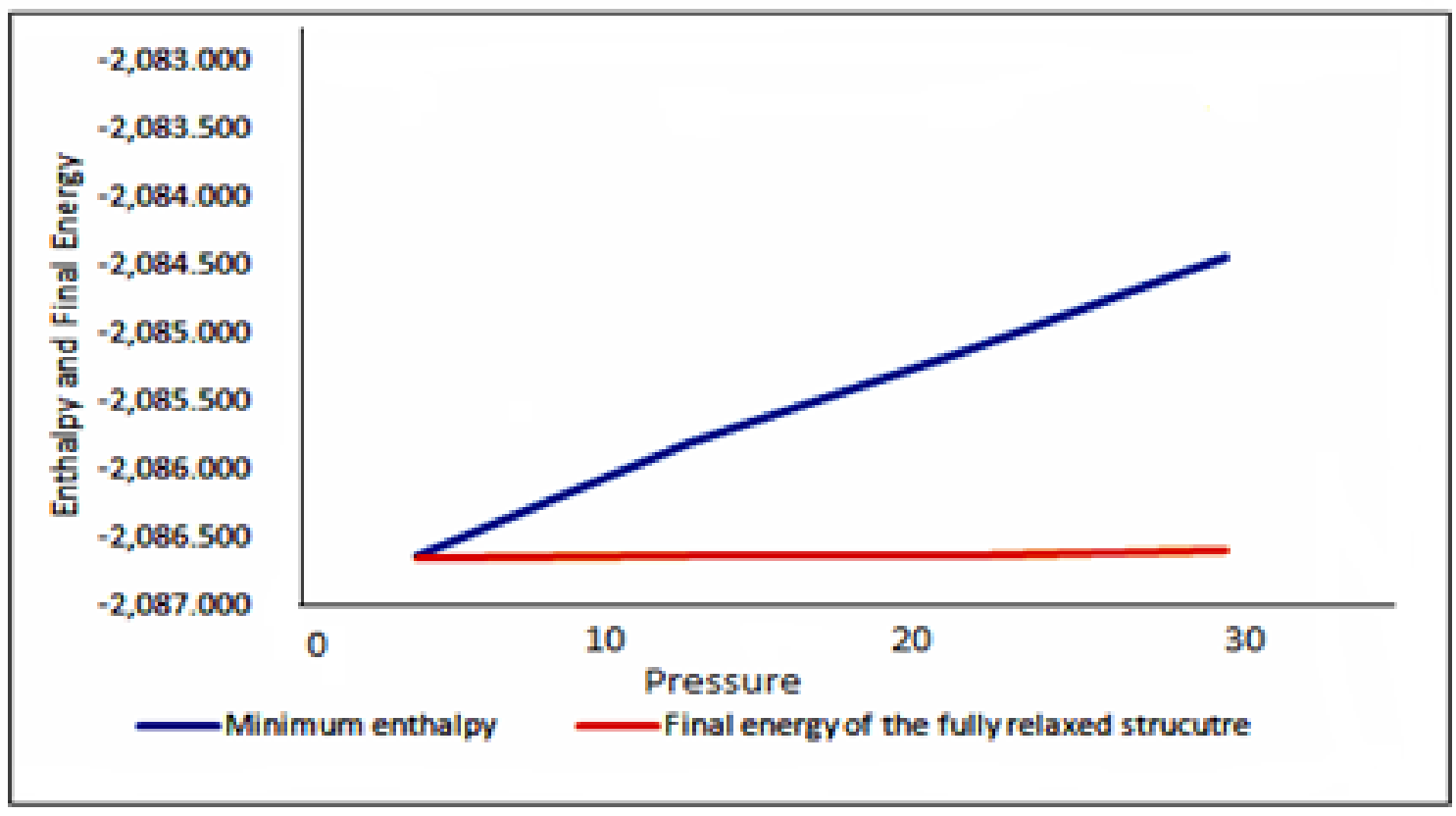

Fig 2. Enthalpy and final energy versus pressure for YBCO Superconductor

\section{Summary/Conclusion}

In summary, the pressure dependence of the elastic constants of the $\mathrm{YBa}_{2} \mathrm{Cu}_{3} \mathrm{O}_{7}$ (YBCO) is investigated using the first principle calculations based on the density functional theory (DFT). The elastic constants $\mathrm{C}_{11}, \mathrm{C}_{22}, \mathrm{C}_{33}, \mathrm{C}_{44}, \mathrm{C}_{55}, \mathrm{C}_{66}, \mathrm{C}_{12}, \mathrm{C}_{13}$ and $\mathrm{C}_{23}$ are calculated at different pressures. In the entire pressure range of our calculations, $\mathrm{C}_{11}=5384 \mathrm{Gpa}, \mathrm{C}_{22}=5804 \mathrm{Gpa}$ and $\mathrm{C}_{33}=$ $4813 \mathrm{Gpa}$, were much larger than those of the other elastic constants, indicating that the deformation resistances of $\mathrm{YBa}_{2} \mathrm{Cu}_{3} \mathrm{O}_{7}$ along the axial directions were stronger than those of the non-axial directions. The elastic constants $\mathrm{C}_{11}, \mathrm{C}_{12}$ and $\mathrm{C}_{44}$ represent the elasticity in length and shape. All the elastic constants increase with pressure. The Enthalpy and final energy of the YBCO Superconductor has also been calculated by using GGA+U ab- initio calculations up to 30GPa. The enthalpy and final energy of YBCO superconductor increases monotonically with pressure.

\section{Acknowledgements}

The authors thank the management at Noida International University for the support to carry out the work.

\section{References}

1) Muller KA, Bednorz JG. Possible HTSC in the Ba-La-Cu-O System. Zeitschriff fur Physik. 1986;64(2):189-193. Available from: https://doi.org/10.107/ BF01303701.

2) Schooley JF, Hosler WR, Cohen LM. Superconductivity in Semiconducting SrTiO3. Physical Review Letters. 1964;12(17):474-475. Available from: https://dx.doi.org/10.1103/physrevlett.12.474.

3) Ledbetter H. Elastic Properties of Metal-Oxide Superconductors. JOM. 1988;40(1):24-30. Available from: https://dx.doi.org/10.1007/bf03258008.

4) Laegreid T, Fossheim K, Sathish S, Vassenden F, Traetteberg O, Sandvold E, et al. Elastic and Thermodynamic Properties of High Temperature Superconductors, a Brief Review. Physica Scripta. 1988;T23:116-118. Available from: https://dx.doi.org/10.1088/0031-8949/1988/t23/020. 
5) Reichardt W, Pintschovius L, Hennion B, Colloin F. Inelastic neutron scattering study of YBa2Cu3O7 Superconducting Science and Technology. 1988;173. Available from: https://doi.org/10.1088/0953-2048/1/4/004.

6) Noel H, Potel M, Tholence JL, Levet JC, Paul MS, Gougeon P. Ultrasound study on YBa2Cu3O7 and GdBa2Cu $3 \mathrm{O} 7$ single crystal, Solid state communications. 1989;69. Available from: https:doi.org/10.1016/0038-1098(89)91055-7.

7) Schneemeyer LF, Golding B, Haemmerle WH. and Gigahertz ultrasound in single crystal superconducting YBa2Cu3O7. In: IEEE 1988 ultrasonic's symposium. IEEE. 1988. Available from: https://doi.org/10.1088/0953-2048/1/4/004.

8) Wallace DC. Thermodynamics of Crystals. Wiley. 1972. Available from: https://doi.org/10.1002/bbpc.19720761121.

9) Barron THK, Klein ML. Proc. Phys. Soc. vol. 85. 1965. Available from: https://doi.org/10.1088/0370-1328/85/3/313.

10) Sin\$rquot\$ko GV, Smirnov NA. Ab initio calculations of elastic constants and thermodynamic properties of bcc, fcc, and hcp Al crystals under pressure. Journal of Physics: Condensed Matter. 2002;14(29):6989-7005. Available from: https://dx.doi.org/10.1088/0953-8984/14/29/301.

11) Kresse G, Furthmüller J. Efficient iterative schemes forab initiototal-energy calculations using a plane-wave basis set. Physical Review B. 1996;54(16):11169-11186. Available from: https://dx.doi.org/10.1103/physrevb.54.11169.

12) Perdew JP, Burke K, Ernzerhof M. GGA made simple. Physics Review Letters. 1996;77. Available from: https://doi.org/10.1103/PhysicsReviewLetters.78. 1396. 